\title{
PENERAPAN MODEL NHT BERBANTU POWERPOINT DALAM MENINGKATKAN KUALITAS PEMBELAJARAN PERENCANAAN PENGAJARAN PADA MAHASISWA KELAS O2PIEM001 PENDIDIKAN EKONOMI, UNIVERSITAS PAMULANG
}

\author{
CANDRA ABDILLAH
}

Dosen Pendidikan Ekonomi, Universitas Pamulang

candra_abdillah@yahoo.com

\begin{abstract}
ABSTRAK
Tujuan penelitian adalah meningkatkan kualitas pembelajaran Perencanaan Pengajaran dengan model NHT berbantu powerpoint pada mahasiswa kelas 02PIEM001 Pendidikan Ekonomi, FKIP, Universitas Pamulang. Pendekatan penelitian yang digunakan adalah mix method, dengan metodologi Penelitian Tindakan Kelas. Adapun desain PTK yang digunakan adalah Kurt Lewin yang terdiri 3 siklus. Subjek penelitian adalah dosen dan mahasiswa kelas 02PIEM001 Pendidikan Ekonomi, FKIP, Universitas Pamulang. Instrumen penelitian ini yaitu lembar observasi keterampilan dasar mengajar dosen, lembar observasi aktivitas mahasiswa, dan soal tes untuk mengetahui prestasi belajar perencanaan pengajaran mahasiswa. Teknik analisis data menggunakan statistika deskriptif. Hasil penelitian menemukan perolehan skor keterampilan dosen pada siklus I yaitu 21 (baik), skor siklus II yaitu 24 (sangat baik), dan skor siklus III 29 (sangat baik). Skor aktivitas mahasiswa pada siklus I yaitu 16,0 (cukup), skor siklus II yaitu 21,7 (baik), dan skor siklus III yaitu 25,2 (sangat baik). Ketuntasan belajar mahasiswa siklus I adalah 50\% (tidak tuntas), siklus II adalah 69\% (tidak tuntas), dan siklus III adalah 85\% (tuntas). Simpulan penelitian adalah model NHT berbantu powerpoint telah meningkatkan kualitas pembelajaran Perencanaan Pengajaran yaitu melalui meningkatnya ketrampilan dosen, aktivitas belajar dan prestasi belajar mahasiswa pada mata kuliah perencanaan pengajaran kelas 02PIEM001 Pendidikan Ekonomi, FKIP, Universitas Pamulang
\end{abstract}

Kata Kunci: kualitas pembelajaran, model NHT, media powerpoint, perencanaan pengajaran 


\section{PENDAHULUAN}

Perencanaan pengajaran merupakan salah satu mata kuliah yang terdapat dalam kurikulum Program Studi Pendidikan Ekonomi, Fakultas Keguruan dan Ilmu Pendidikan, Universitas Pamulang. Mata kuliah Perencanaan Pengajaran memberi bekal pengetahuan dan keterampilan menyusun perangkat pembelajaran yang baik untuk persiapan mengajar. Perangkat pembelajaran yang dikembangkan oleh mahasiswa berupa program tahunan, program semester, silabus, rencana pelaksanaan pembelajaran (RPP), dan penilaian.

Namun pada kenyataannya pembelajaran pada perencanaan pengajaran belum sesuai dengan yang diharapkan, masih banyak ketimpangan. Permasalahan pada pembelajaran perencanaan pengajaran tersebut adalah mahasiswa belum aktif saat pembelajaran dan prestasi belajarnya rendah. Hal ini dibuktikan dengan pada nilai mahasiswa pada ulangan tengah semester ganjil 2018/2019 yang belum maksimal. Kriteria ketuntasan minimal (KKM) yang ditentukan yaitu 70. Hasil evaluasi dari 26 mahasiswa, mahasiswa yang tuntas KKM sebanyak 11 mahasiswa (42\%), dan mahasiswa tidak tuntas KKM sebanyak 14 mahasiswa (58\%). Rendahnya hasil belajar pada mahasiswa kelas 02PIEM001 menunjukkan bahwa kualitas pembelajaran perencanaan pengajaran masih rendah.
Berdasarkan hasil observasi dan refleksi yang telah dilakukan, permasalahan tersebut dipengaruhi beberapa faktor, yaitu dosen mengajar hanya menggunakan metode ceramah dan tidak menggunakan media pembelajaran yang sesuai. Dosen dalam mengajar kurang menunjukkan interaksi dan komunikasi dengan mahasiswa, sehingga pembelajaran hanya berfokus pada dosen. Dosen belum menerapkan model pembelajaran yang dapat meningkatkan keaktifan mahasiswa dalam pembelajaran perencanaan pengajaran. Masalah yang berkaitan dengan aktivitas mahasiswa kelas 02PIEM001 menunjukkan bahwa mahasiswa tidak berpartisipasi aktif dalam pembelajaran sehingga prestasi belajar yang dihasilkan rendah.

Berdasarkan permasalahan yang ditemukan oleh peneliti yaitu rendahnya kualitas pembelajaran perencanaan pengajaran di kelas 02PIEM001 Prodi Pendidikan Ekonomi Universitas Pamulang, untuk memperbaiki kualitas pembelajaran tersebut maka ditetapkan alternatif tindakan berupa penerapan model NHT dengan media powerpoint. Melalui model dan media tersebut diharapkan dapat meningkatkan kualitas pembelajaran dengan meningkatkan keterampilan dasar mengajar dosen dan meningkatkan aktivitas mahasiswa sehingga akan berdampak meningkatnya prestasi belajar mahasiswa. 
Model NHT merupakan singkatan dari Numbered Heads Together. Penerapan model NHT pada perencanaan pengajaran, dosen dapat melibatkan lebih banyak mahasiswa dalam diskusi kelompok dengan tiap mahasiswa memiliki nomor tertentu untuk menelaah dan mengembangkan perangkat pembelajaran dan mengecek pemahaman mereka terhadap meteri mata kuliah perencanaan pengajaran tersebut dengan memanggil nomor kepala pada mahasiswa secara acak, sehingga dalam pembelajaran perencanaan pengajaran setiap mahasiswa akan berdiskusi secara sungguh-sungguh dalam pengembangan perangkat pembelajaran. Hal ini diperkuat oleh pendapat Hamdani (2011:89) bahwa model pembelajaran NHT, mahasiswa melakukan kompetisi agar dapat mendorong mahasiswa untuk lebih bersemangat dalam belajar.

Model NHT ditunjang dengan media powerpoint. Powerpoint merupakan program yang biasa digunakan pendidik untuk presentasi materi ajar. Materi ajar tersebut bisa berupa teks, gambar, hingga video pembelajaran. Pembelajaran perencanaan pengajaran melalui penggunaan media powerpoint akan lebih menarik sehingga dapat tersimpan dalam memori jangka panjang mahasiswa. Melalui media powerpoint mahasiswa juga akan mudah memahami materi ajar Perencanaan Pengajaran daripada hanya mendengarkan ceramah dari dosen saja. Sehingga, penerapan model NHT berbantu media powerpoint bisa lebih variatif dan meningkatkan interaksi antara dosen dan mahasiswa.

Peneliti terdahulu yang relevan dengan penelitian ini antara lain: Lince (2016) dan Sari (2017) menunjukkan bahwa model NHT telah meningkatkan kemampuan berpikir kreatif dan hasil belajar siswa. Erdemir (2011) mengemukakan bahwa penerapan media powerpoint telah meningkatkan aktivitas dan prestasi belajar mahasiswa. Anggara (2016) yang menunjukkan bahwa model pembelajaran think pair share berbantu media powerpoint dapat meningkatkan kualitas pembelajaran Matematika Ekonomi.

Berdasarkan uraian di atas maka akan dikaji penelitian tindakan kelas dengan judul Penerapan Model NHT Berbantu Powerpoint dalam Meningkatkan Kualitas Pembelajaran Perencanaan Pengajaran Pada Mahasiswa Kelas 02PIEM001 Pendidikan Ekonomi, Universitas Pamulang. Adapun rumusan masalah yang diajukan sesuai dengan permasalahan di atas adalah sebagai berikut: Bagaimana cara meningkatkan kualitas pembelajaran Perencanaan Pengajaran pada mahasiswa kelas 02PIEM001 Pendidikan Ekonomi Universitas Pamulang?. Adapun rincian rumusan masalah tersebut adalah sebagai berikut: Bagaimana penerapan model NHT berbantu powerpoint untuk meningkatkan keterampilan dasar 
mengajar dosen? Bagaimana penerapan model NHT berbantu powerpoint untuk meningkatkan aktivitas mahasiswa? Bagaimana penerapan model NHT berbantu powerpoint dalam meningkatkan prestasi belajar mahasiswa?

\section{METODE PENELITIAN}

Pendekatan penelitian yang digunakan adalah mix method, dengan metodologi penelitian tindakan kelas. Adapun desain PTK menggunakan Kurt Lewin sebanyak 3 siklus dengan masing-masing siklus terdiri 4 tahap, yaitu (1) tahap perencanaan; (2) tahap pelaksanaan; (3) tahap pengamatan; dan (4) tahap refleksi.

Subjek penelitian adalah dosen mata kuliah perencanaan pengajaran dan mahasiswa kelas 02PIEM001 Pendidikan Ekonomi, FKIP, Universitas Pamulang yang berjumlah 26 mahasiswa yang terdiri dari 13 mahasiswa perempuan dan 13 mahasiswa laki-laki.

Teknik dan instrumen pengumpul data pada penelitian ini disajikan pada Tabel 1.

Tabel 1. Teknik dan Instrumen

\begin{tabular}{|c|c|c|}
\hline Jenis Data & Teknik & Instrumen \\
\hline $\begin{array}{l}\text { Keterampilan } \\
\text { dasar } \\
\text { mengajar } \\
\text { dosen }\end{array}$ & $\begin{array}{l}\text { Observas } \\
\text { i }\end{array}$ & $\begin{array}{l}\text { Lembar observasi } \\
\text { keterampilan } \\
\text { dasar mengajar } \\
\text { dosen }\end{array}$ \\
\hline $\begin{array}{l}\text { Aktivitas } \\
\text { mahasiswa }\end{array}$ & $\begin{array}{l}\text { Observas } \\
\mathrm{i}\end{array}$ & $\begin{array}{l}\text { Lembar observasi } \\
\text { aktivitas } \\
\text { mahasiswa }\end{array}$ \\
\hline $\begin{array}{l}\text { Prestasi } \\
\text { belajar }\end{array}$ & Tes & Soal tes \\
\hline
\end{tabular}

perencanaan

pengajaran

Teknik analisis data menggunakan statistika deskriptif terdiri dari penyajian data, mean, persentil, dan range. Statistika deskriptif pada penelitian ini hanya menerangkan kelompok data hasil saja tanpa mengeneralisasikan.

\section{HASIL DAN PEMBAHASAN}

Keterampilan dosen, aktivitas dan prestasi belajar mahasiswa pada Perencanaan Pengajaran pada siklus I, II dan III selalu mengalami peningkatan. Berikut ini akan digambarkan peningkatan keterampilan dosen, aktivitas dan prestasi belajar mahasiswa pada perkuliahan Perencanaan Pengajaran dengan model NHT berbantu powerpoint pada siklus I, II, dan III.

\section{Keterampilan Dosen}

Keterampilan

dosen merupakam usaha yang dilakukan oleh dosen melalui bahan pengajaran yang diarahkan untuk perubahan kognitif mahasiswa dalam peningkatan pembelajaran Perencanaan Pengajaran dengan model NHT berbantu powerpoint. Rekapitulasi perolehan skor keterampilan dosen tiap siklus ditunjukkan Gambar 1. 


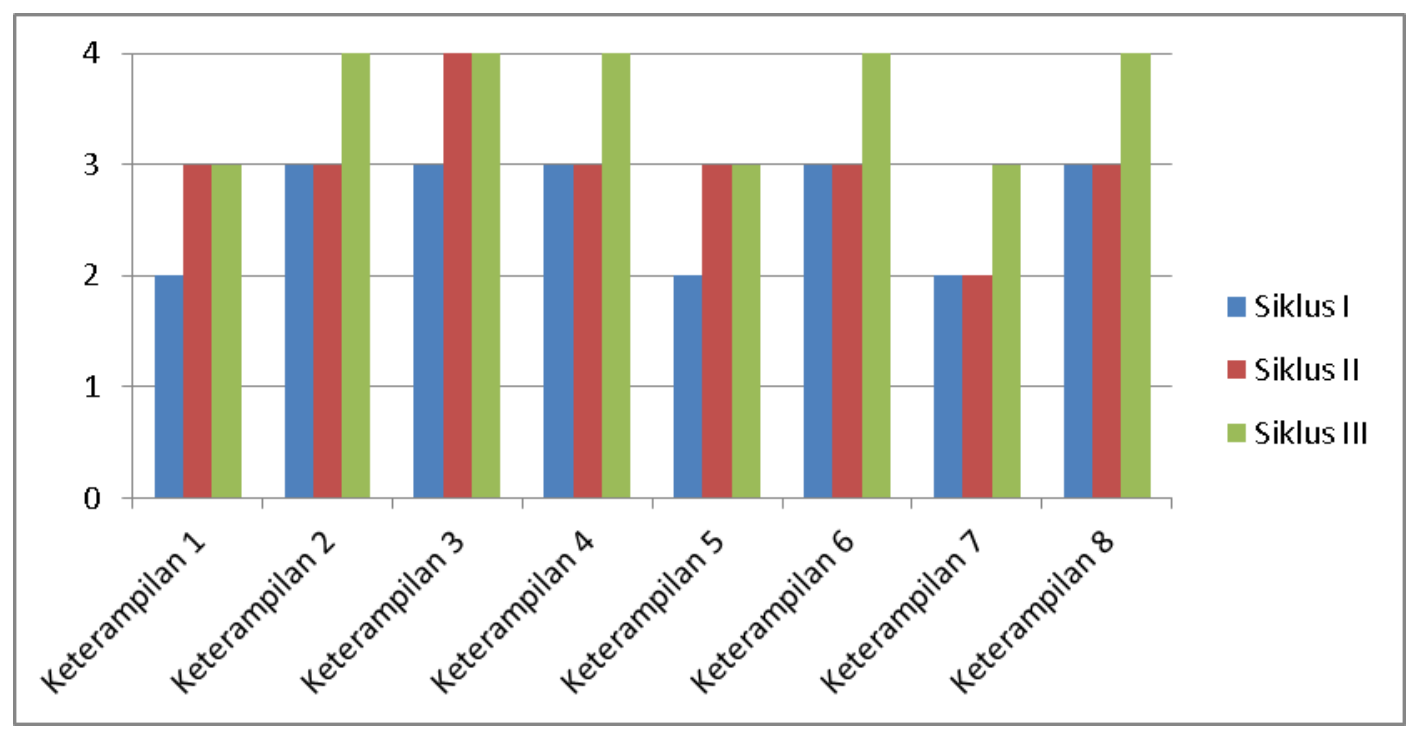

Gambar 1. Skor Keterampilan Dasar Mengajar Dosen

\section{Keterangan :}

Keterampilan 1 : Keterampilan membuka pembelajaran Perencanaan Pengajaran Keterampilan 2 : Keterampilan menggunakan media powerpoint

Keterampilan 3 : Keterampilan bertanya materi Perencanaan Pengajaran

Keterampilan 4 : Keterampilan membimbing diskusi kelompok menggunakan model NHT

Keterampilan 5 : Keterampilan membimbing presentasi dan tanggapan hasil diskusi

Keterampilan 6 : Keterampilan mengajar Perencanaan Pengajaran menggunakan model NHT

Keterampilan 7 : Keterampilan memberikan penguatan

Keterampilan 8 : Keterampilan menutup pelajaran

Berdasarkan Gambar 1, ditunjukkan bahwa hasil observasi keterampilan dasar mengajar dosen pada pembelajaran Perencanaan Pengajaran dengan menerapkan model NHT berbantu powerpoint dari siklus I, II, dan III mengalami peningkatan. Keterampilan dosen pada siklus I memperoleh skor 21 (baik), keterampilan dosen pada siklus II memperoleh skor 24 (sangat baik), dan keterampilan dosen pada siklus III memperoleh skor 29 (sangat baik).

\section{Aktivitas Mahasiswa}

Aktivitas mahasiswa dalam penelitian ini adalah segala kegiatan yang dilakukan dalam proses interaksi (dosen dan mahasiswa) yang menekankan keaktifan secara fisik, mental intelektual dan emosional guna untuk memperoleh hasil belajar yang maksimal dalam pembelajaran

Perencanaan 
Pengajaran dengan model NHT berbantu powepoint. Peningkatan perolehan skor keaktifan mahasiswa pada tiap siklus ditunjukkan pada Gambar 2.

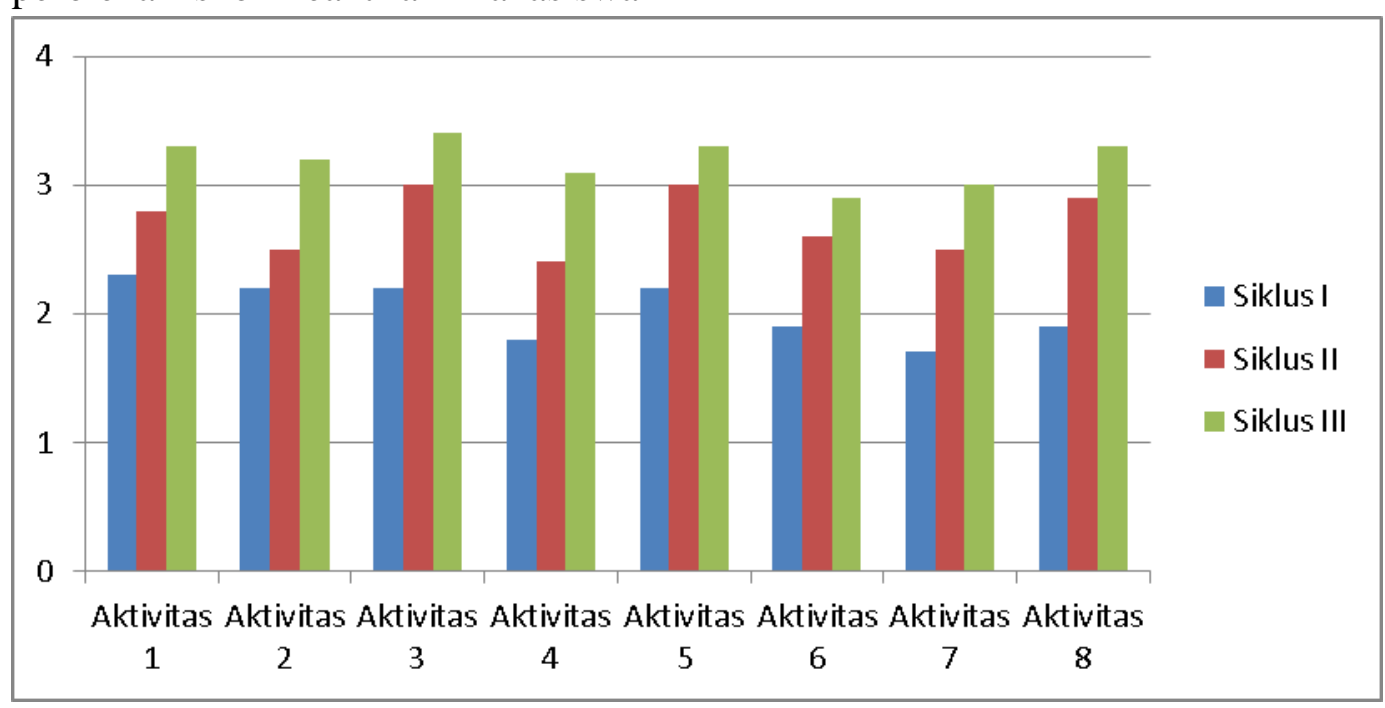

Gambar 2. Skor Aktivitas Mahasiswa Keterangan:

Aktivitas $1:$ Kesiapan menerima pembelajaran

Aktivitas 2 : Melaksanakan perintah dosen dalam pembentukan kelompok Aktivitas 3 : Memperhatikan penjelasan dosen Aktivitas 4 : Bertanya dan menjawab pertanyaan dari dosen Aktivitas 5 : Keaktifan dalam diskusi kelompok Aktivitas 6 : Kemampuan mempresentasikan hasil diskusi Aktivitas 7 : Kemampuan menanggapi hasil diskusi kelompok lain Aktivitas 8 : Kemampuan menyimpulkan materi pembelajaran

Berdasarkan Gambar 2, hasil observasi aktivitas mahasiswa pada Perencanaan Pengajaran dengan model NHT berbantu powerpoint dari siklus I, II, dan III mengalami peningkatan. Aktivitas mahasiswa pada siklus I memperoleh skor 16,0 (cukup), aktivitas mahasiswa pada siklus II memperoleh skor 21,7 (baik), dan aktivitas mahasiwa pada siklus III memperoleh skor 25,2 (sangat baik).

\section{Prestasi Belajar dalam Pembelajaran Perencanaan Pengajaran}

Berdasarkan hasil penelitian dapat dilihat bahwa terdapat peningkatan prestasi belajar Perencanaan Pengajaran dengan menerapkan model NHT berbantu powerpoint dari siklus I sampai siklus III. Hal ini dibuktikan dengan kenaikan persentase ketuntasan prestasi belajar antara siklus I dan siklus II sebesar 19\%. Sedangkan persentase ketuntasan prestasi belajar 
antara siklus II dan siklua III adalah sebesar 16\%. Berdasarkan data tersebut, dapat disimpulkan prestasi belajar mahasiswa kelas 02PIEM001 sudah memenuhi kriteria ketuntasan klasikal (>85\%). Prestasi belajar mahasiswa pada tiap siklus ditunjukkan Tabel 2.

Tabel 2. Prestasi Belajar Mahasiswa pada tiap siklus

\begin{tabular}{|c|c|c|c|c|}
\hline No. & Pencapaian & Siklus I & Siklus II & Siklus III \\
\hline 1. & Nilai Rata-Rata Kelas & 74,4 & 81,2 & 87,6 \\
\hline 2. & Nilai Tertinggi & 80 & 90 & 100 \\
\hline 3. & Nilai Terendah & 50 & 55 & 65 \\
\hline 4. & Mahasiswa Memenuhi KKM & 13 & 18 & 22 \\
\hline 5. & Mahaiswa Belum Memenuhi KKM & 13 & 8 & 4 \\
\hline 6. & Persentase Ketuntasan Belajar Klasikal & $50 \%$ & $69 \%$ & $85 \%$ \\
\hline
\end{tabular}

Penelitian sebelumnya oleh Abdillah (2017) menunjukkan bahwa model pembelajaran yang berpendekatan student centered telah meningkatkan keterampilan proses dan pemahaman konsep siswa. Anggara (2016) dan Erdemir (2011) mengemukakan bahwa penerapan model pembelajaran kooperatif dengan media powerpoint telah meningkatkan aktivitas dan prestasi belajar mahasiswa. Haydon (2010), Hunter (2015), dan Leasa (2017) mengemukakan bahwa penerapan model NHT dapat meningkatkan aktivitas belajar dan prestasi belajar siswa.

Penelitian ini membuktikan bahwa model NHT berbantu powerpoint juga dapat meningkatkan prestasi belajar mahasiswa pada pembelajaran Perencanaan Pengajaran. Berdasarkan penelitian yang telah dilakukan, terlihat bahwa terjadi peningkatan keterampilan dosen, aktivitas mahasiswa, prestasi belajar mahasiswa pada pembelajaran Perencanaan Pengajaran di kelas 02PIEM001 Pendidikan Ekonomi, Fakultas Keguruan dan Ilmu Pendidikan Universitas Pamulang. Hal ini disebabkan karena model NHT adalah model yang menuntut mahasiswa agar selalu siap dan sungguh-sungguh memahami materi ajar karena dosen sewaktu-waktu dapat menunjuk nomor mahasiswa secara acak. Sehingga berdampak pengetahuan yang didapatkan mahasiswa menjadi lebih bermakna dan prestasi belajar meningkat.

\section{KESIMPULAN}

Berdasarkan analisis dan pembahasan hasil penelitian dapat disimpulkan bahwa penerapan model NHT berbantu powerpoint dapat 
memperbaiki kualitas pembelajaran Perencanaan Pengajaran kelas 02PIEM001 Prodi Pendidikan Ekonomi Universitas Pamulang dengan indikator yaitu meningkatnya keterampilan dosen, meningkatnya aktivitas dan prestasi belajar mahasiswa.

Saran yang diberikan berdasarkan hasil penelitian adalah sebagai berikut: sebaiknya dosen menerapkan model dan media yang inovatif dalam mengajar agar aktivitas mahasiswa meningkat sehingga prestasi belajar juga meningkat. Dosen juga sebaiknya mempersiapkan media ajar dengan optimal sesuai dengan alokasi waktu yang tersedia.

\section{REFERENSI}

Abdillah, C., Linuwih, S., \& Isnaeni, W. (2017). The Effectiveness of Model Learning Preser-X Assisted LKS Against Science Process Skills and Understanding Students Concept. Journal of Primary Education, 6(3), 192-199.

Anggara, D. S. (2016). Peningkatan Kualitas Pembelajaran

Matematika Ekonomi Melalui Model Think Pair Share Dengan Media Powerpoint Pada Mahasiswa Kelas 03pie papendidikan ekonomi Universitas pamulang.pekobis Jurnal Pendidikan, Ekonomi dan Bisnis, 2(2), 12-20.
Erdemir, N. (2011). The Effect of PowerPoint and Traditional Lectures on Students' Achievement in Physics. Journal of Turkish Science Education (TUSED), 8(3).

Hamdani. (2011). Strategi Belajar Mengajar. Bandung: Pustaka Setia.

Haydon, T., Maheady, L., \& Hunter, W. (2010). Effects of numbered heads together on the daily quiz scores and on-task behavior of students with disabilities. Journal of Behavioral Education, 19(3), 222-238.

Hunter, W. C., Maheady, L., Jasper, A. D., Williamson, R. L., Murley, R. C., \& Stratton, E. (2015). Numbered heads together as a tier 1 instructional strategy in multitiered systems of support. Education and Treatment of Children,38(3), 345-362.

Leasa, M., \& Corebima, A. D. (2017). The effect of numbered heads together (NHT) cooperative learning model on the cognitive achievement of students with different academic ability. In Journal of Physics: Conference Series (Vol. 795, No. 1, p. 012071). IOP Publishing.

Lince, R. (2016). Creative Thinking Ability to Increase Student Mathematical of Junior High School by Applying Models 
Numbered

Heads

Together. Journal of Education and Practice,7(6), 206-212.

Sari, M., \& Surya, E. (2017). Improving the Learning Outcomes of Students using Numbered Heads Together Model in the Subjects of Mathematics. International

Journal of Sciences: Basic and Applied Research (IJSBAR), 33(03), 311-3 